\section{The effectiveness of biofeedback in treatment of women with stress urinary incontinence: a systematic review}

\section{Eficácia do biofeedback no tratamento de mulheres com incontinência urinária de esforço: revisão sistemática}

Leila Maria Alvares Barbosa 1

Deniele Bezerra Lós 2

Ivson Bezerra da Silva 3

Caroline W. S. Ferreira Anselmo 4

\begin{abstract}
Objectives: to assess whether pelvic-floor muscle training associated with biofeedback is more effective in the treatment of women with stress urinary incontinence, when compared to exercise alone.

Methods: a research of articles published in the last 20 years in Lilacs, PubMed and SCIRUS databases, using the descriptors "urinary incontinence, stress" and "biofeedback" was conducted. Randomized clinical trials comparing pelvic-floor muscle training with and without biofeedback were included.

Results: the study involved three randomized clinical trials involving 169 patients. A physical therapist was responsible for conducting the treatment using electromyographic or pressure biofeedback, and exercises were performed in the clinic or at home. The assessment methods, treatment times and protocols used were heterogeneous. Statistical analysis and rates of cure/improvement were similar between the groups of articles analyzed. Two studies had a score 8, and the third had 6 points according to PEDro's Scale.

Conclusions: examination of the studies found suggests that adding biofeedback to pelvic-floor muscle training appears not to bring about a significant difference in terms of the success of treatment, when compared to perineal exercises performed in isolation.
\end{abstract}

Key words Urinary incontinence, stress, Biofeedback, Exercise therapy

\footnotetext{
1-4 Departamento de Fisioterapia. Centro de Ciências da Saúde. Universidade Federal de Pernambuco. Av. Prof. Moraes Rego, 1235. Cidade Universitária. Recife, PE, Brasil. CEP: 50670-901.

E-mail: leilabarbosa.fisio@gmail.com.
}

\section{Resumo}

Objetivos: verificar se os exercícios para a musculatura do assoalho pélvico (MAP) associados ao biofeedback promovem maior eficácia no tratamento da incontinência urinária de esforço em mulheres, quando comparados a cinesioterapia de forma isolada.

Métodos: foi realizada uma pesquisa dos artigos publicados nos últimos 20 anos, nas bases de dados Lilacs, PubMed e SCIRUS, através dos descritores "urinary incontinence, stress" e "biofeedback". Foram incluidos ensaios clínicos aleatorizados que utilizaram como intervenção exercícios para a MAP isolados e associados ao biofeedback, de forma comparativa.

Resultados: foram incluidos três ensaios clínicos randomizados envolvendo 169 pacientes. O fisioterapeuta foi responsável por conduzir o tratamento utilizando biofeedback eletromiográfico ou pressórico, e os exercícios foram realizados no ambulatório ou orientados para casa. Verificou-se heterogeneidade quanto ao método de avaliação, tempo de tratamento e protocolos utilizados. As análises estatisticas e os indices de cura/melhora foram semelhantes entre os grupos dos artigos analisados. Dois estudos obtiveram pontuação igual a oito e o terceiro alcançou seis pontos de acordo com a Escala PEDro.

Conclusões: a análise dos estudos encontrados sugere que a adição do biofeedback aos exercícios perineais parece não promover diferença significativa para o sucesso do tratamento, quando comparado aos exercícios perineais realizados de forma isolada.

Palavras-chave Incontinência urinária de esforço, Biorretroalimentação, Terapia por exercício 


\section{Introduction}

Stress urinary incontinence (SUI) is defined as the involuntary loss of urine during physical exercise, sneezing or coughing. ${ }^{1}$ In practical terms, SUI can occur as a result of hypermobility of the bladder neck and proximal urethra or by sphincter failure. As it is considered an anatomical incontinence, the main structures that can be damaged in hypermobility of the bladder neck are the pelvic-floor muscles, the endopelvic fascia and the ligaments. ${ }^{2}$

The prevalence of SUI is approximately $23.7 \%$ of the population, reaching a peak in the fifth decade of life. ${ }^{3}$ Risk factors that may damage such structures and lead to weakness of the seat of the pelvis include childbirth, vaginal birth, hysterectomy, hormone changes, body mass index (BMI) obesity, chronic cough and type of physical activity.4-5

In recent years, non-surgical treatment of SUI has received special attention. Some studies point to evidence that exercises involving the perineal muscles, electrostimulation, the use of vaginal cones and biofeedback are effective in treating this disorder.6-9

Exercises for the pelvic-floor muscles (PFM), also known as kinesiotherapy, have been used for conservative treatment of SUI for over 60 years, since Kegel,10 in 1948, presented his results. Recently, a systematic review was published as a way of determining the effects of training of the pelvic-floor muscles in incontinent women. 11 These authors concluded that the studies selected suggested that greater therapeutic effectiveness could be found in the treatment of women with SUI who took part in a program of kinesiotherapy for the perineal muscles.

At present, biofeedback is one of the most commonly used procedures in clinical practice to retrain the perineal muscles, showing the incontinent woman by way of visual signs and/or sounds which group of muscles is to be worked on. 12 Various studies in which the patient was able to follow the treatment protocol in special clinics or at home have been conducted, using the pressure or electromyographic biofeedback device. Both types of biofeedback were shown to be effective in treating SUI.13-14

Conservative treatment with kinesiotherapy in association with the use of biofeedback seems to be a good practice, in view of the possibility of reducing the intensity of the symptoms and reducing the need for surgery, and thereby promoting the social rehabilitation of the incontinent patient. This systematic review aims to examine whether exercises for the PFM in association with biofeedback constitute a more effective treatment of SUI in women, compared to kinesiotherapy for PFM alone.

\section{Methods}

A computerized bibliographical study was carried out in May and April 2010. The selected articles were published between 1980 and 2010. in the Lilacs, PubMed and SCIRUS databases. The descriptors used for the research, based on the Medical Subjects Heading (MeSH), were "urinary incontinence, stress" and "biofeedback", with the Boolean operator "AND" between the words. To facilitate the search for articles, it was limited to "humans" and "female".

The study covered randomized clinical trials published in English, Portuguese and Spanish. It was restricted to female patients, aged over 18 years, who had been diagnosed with stress urinary incontinence. It should be pointed out that the articles selected were restricted to those where exercise of the pelvic-floor muscles in isolation or in association with biofeedback, in a comparative fashion. The protocol used (type of biofeedback, description of PFM exercises, length of therapy and number of sessions), and the professional who conducted the treatment needed specification.

Likewise, the articles had to include a description of the clinical outcome and the methods used to evaluate patients using at least one of the following methods: evaluation of the strength of the PFM, an urodynamic study, pad test bladder diary, evaluation of urinary loss, an evaluation of social activity and a quality of life questionnaire.

Articles that used as it sample patients with neurological disorders or those with other types of incontinence or pregnant women were excluded, along with studies that used another kind of conservative treatment and/or surgery for SUI.

The information contained in the studies found was evaluated by independent reviewers. At first, relevant articles were identified from the title and abstract. A second, more detailed analysis of the text was carried out to establish whether the studies could be included in the systematic review. In the case of disagreements a third reviewer was consulted. The quality of the methodology of the clinical trials was established by way of analysis carried out by the reviewers, taking as their point of reference the PEDro scale descriptors. 15 The PEDro scale assesses 11 items, although only ten are give points. The clinical trial was thus given a score from 0 to 10 . For inclusion in this review, the clinical trial needed to attain a score of more than five points. 


\section{Results}

311 articles were found in the electronic databases Ten studies were selected for full evaluation of the text. Six of these were excluded, two for including in the sample patients with mixed urinary incontinence, two for not having used the same exercise protocol for the two groups, with the groups being differentiated only by the addition of biofeedback in the treatment group, one for having assigned patients to the feedback control group on the basis of touching the vaginal and abdominal regions, and one for including a group undergoing hormone treatment. A seventh article was excluded for attaining a score of only 3 on the PEDro scale. Finally, three randomized clinical trials involving 169 patients in total were chosen for more detailed analysis: Berghmans et al.,16 Morkved et al.,17 e Aukee et al. 18 (Figure 1).

Table 1 shows the characteristics of the selected studies. Tables 2 and 3 describe the PFM exercises and the results of the analysis of the studies, respectively.

Figure 1

Flowchart of search process and selection of articles.
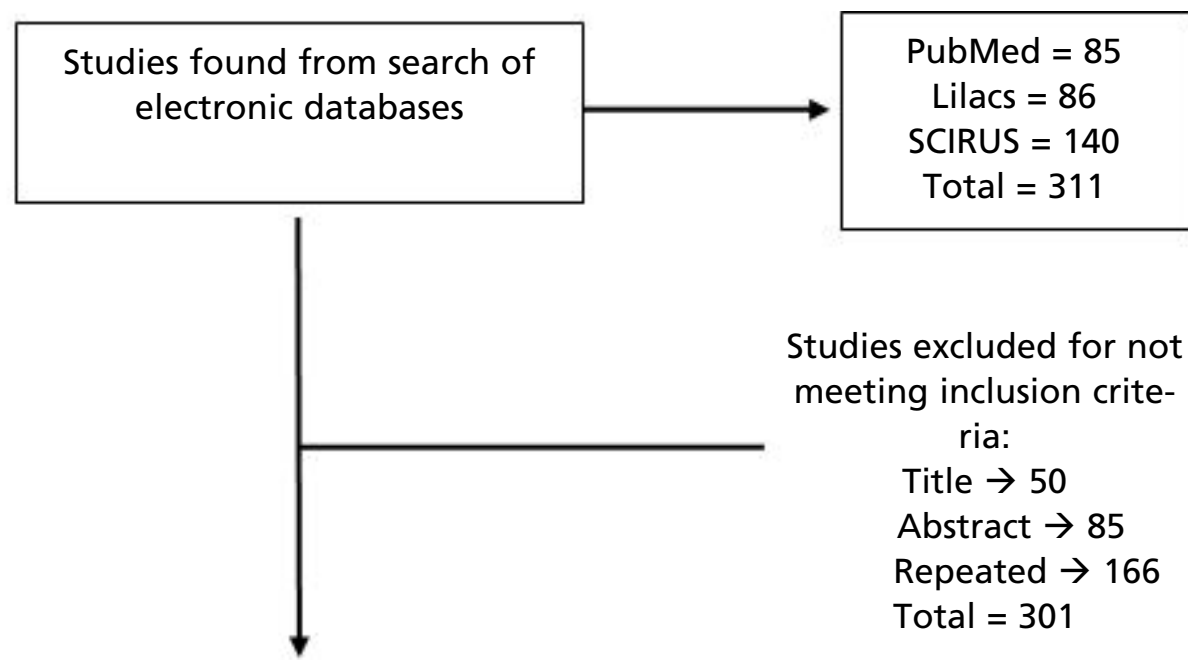

Studies excluded for not meeting inclusion crite-

ria:

Title $\rightarrow 50$

Abstract $\rightarrow 85$

Repeated $\rightarrow 166$

Total $=301$

\section{Studies obtained after detailed analysis$$
\mathrm{n}=10
$$

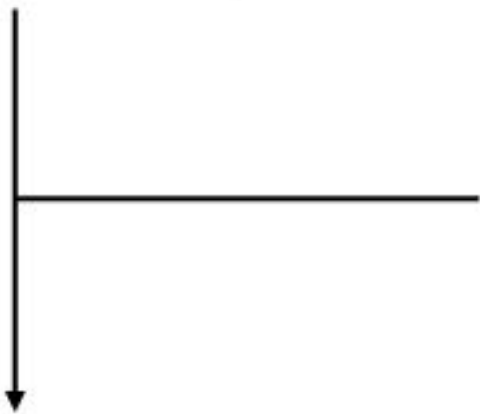

Studies excluded for not meeting the inclusion criteria:

Text $\rightarrow 06$

PEDro Scale Score $\rightarrow 01$

Total $=07$

Studies included for analysis in systematic review: $n=03$

- Berghmans et al.,161996 (PubMed, Lilacs, SCIRUS)

- Morkved et al.,17 2002 (PubMed, Lilacs, SCIRUS)

- AUKEE et al.,18 2004 (SCIRUS) 


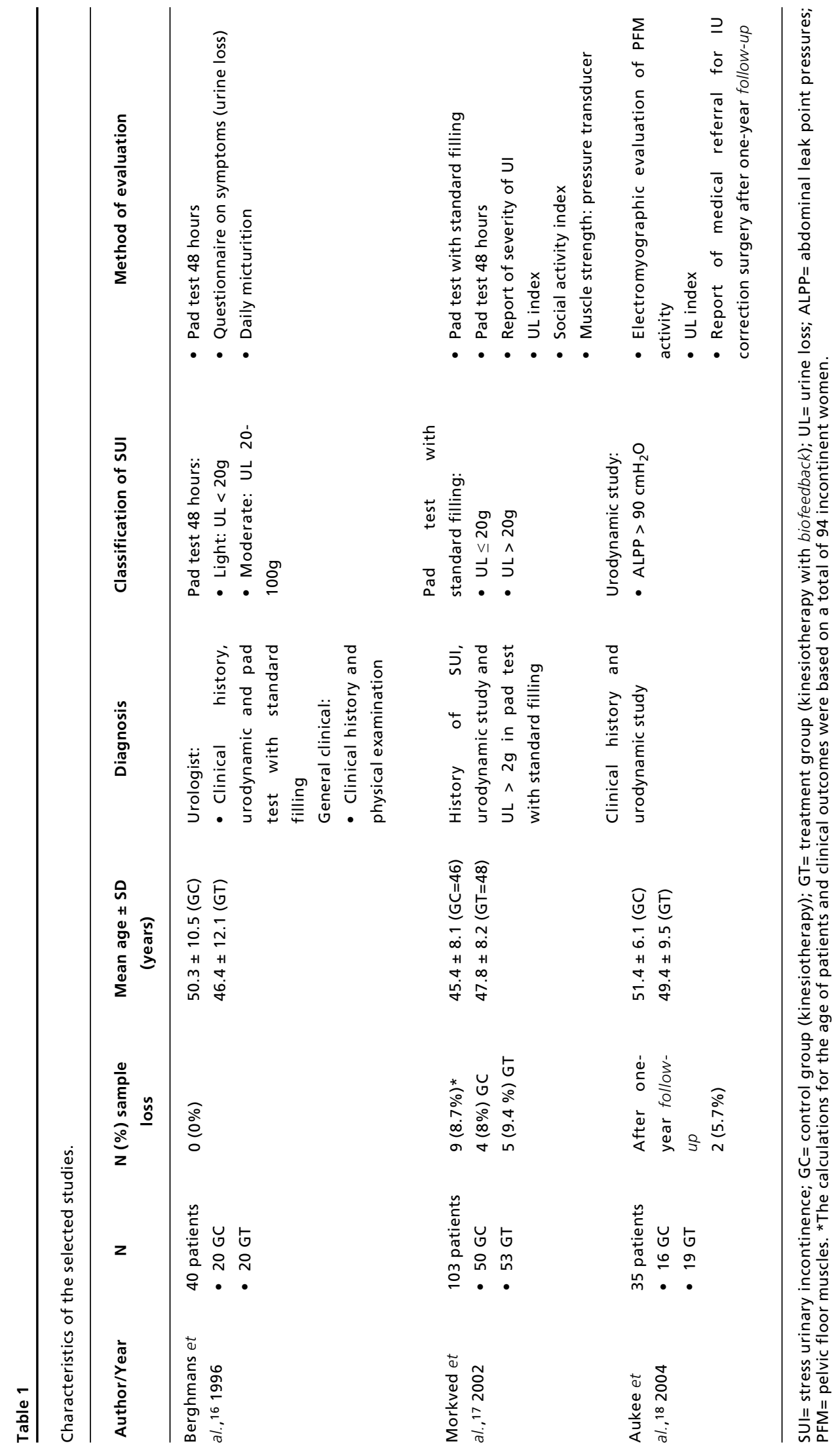




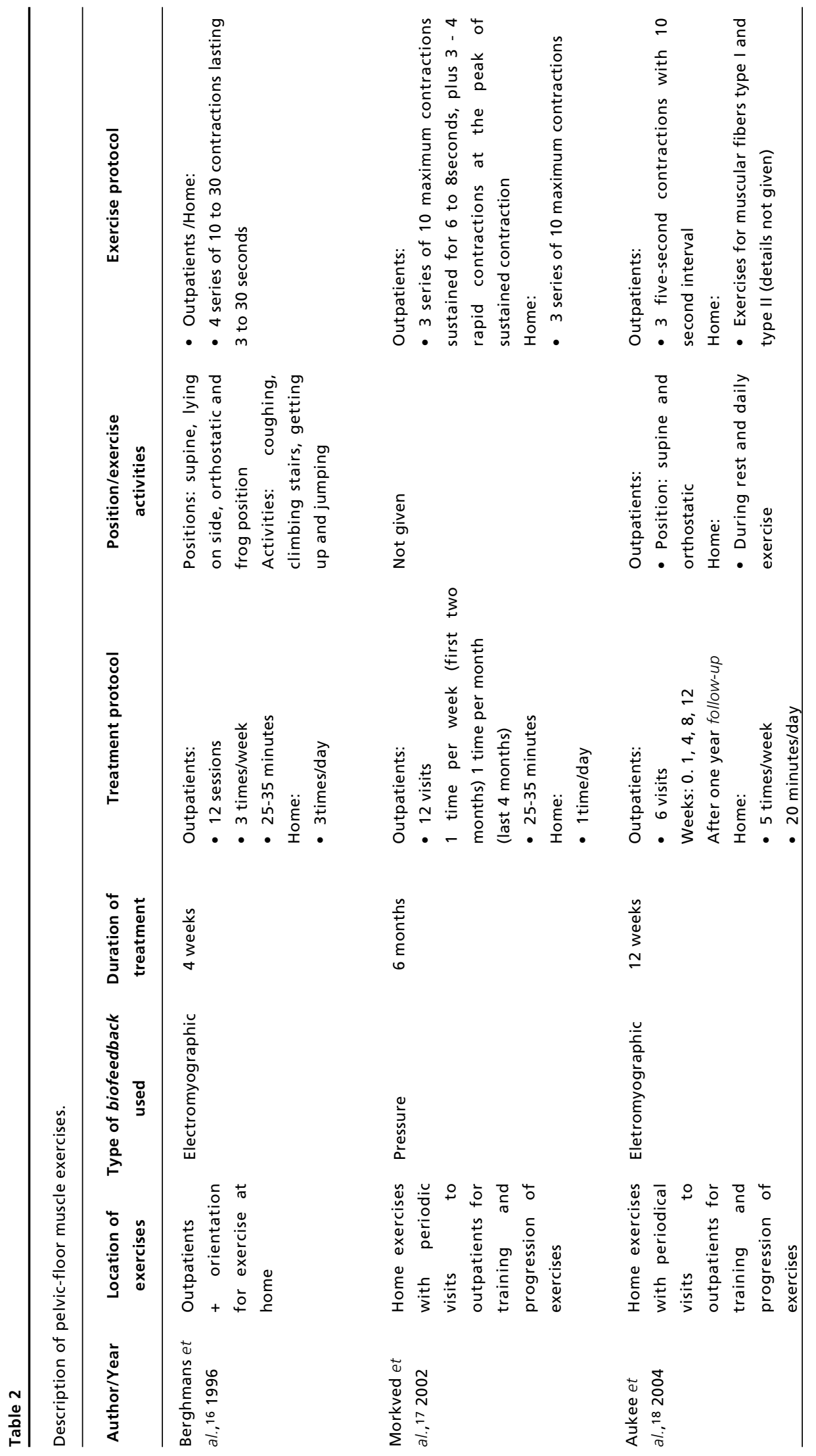




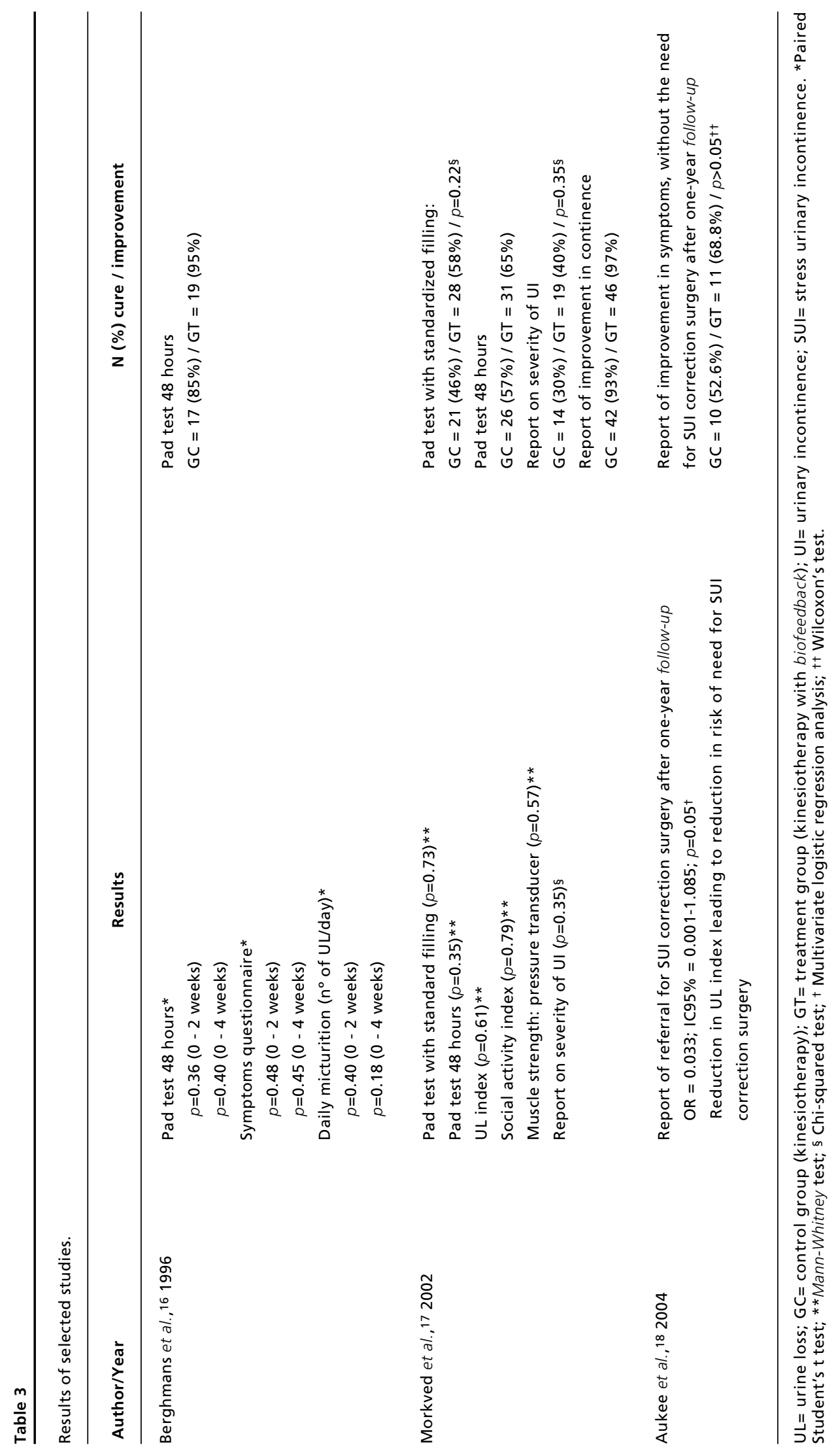


So far as the quality of the methodology of the articles was concerned, two articles ${ }^{16-17}$ received a score of eight and the third 18 a score of six on the PEDro scale. In all the articles, one physiotherapist was the professional responsible for conducting the treatment and the patients received explanations regarding the anatomy of the pelvis and the contraction of the pelvic-floor muscles.

\section{Discussion}

The present review suggests that non-medication based conservative treatment - kinesiotherapy in isolation or in association with biofeedback - of SUI has been shown to be effective. However, it can be seen that there have been an insufficient number of randomized clinical trials dealing with this subject. Only three studies were included in this review and it was observed that the evaluation methods and treatment protocols were still quite heterogeneous.

None of the articles examined can be considered double-blind, since both the patient and the therapist were aware of the kind of treatment that was being given. Only the assessors were blind, which is why these studies did not receive the maximum score on the scale. It can be considered that the studies are good in terms of methodology, since they received a score of over $50 \%$ overall on the scale.

The mean age of the patients who received treatment was similar. The women included had a clinical history of urine loss under stress, which was confirmed by urodynamic examination. Only one of the studies examined 16 partially included in the sample patients with a diagnosis of SUI based on clinical history and physical examination. In one of the articles selected 17 some patients reported symptoms of urgency-incontinence, which was not confirmed by urodynamic examination. In two of the studies ${ }^{16-17}$ the degree of severity of the SUI was stratified according to the results of the pad test. The International Continence Society (ICS) and the International Urogynecological Association (IUGA) recommend that the investigation and classification of UI be carried out by a combination of the patientreported symptoms and the results of a urodynamic examination. 19

Objective evaluation of the improvement in urinary continence also varied among these studies. The functioning of the PFM was assessed by way of a pressure transducer ${ }^{17}$ and the quantity of urine loss was evaluated using the pad test with standard bladder filling 17 or during 48 hours. ${ }^{16-17}$ In one of the studies selected, 18 the authors conducted a reevaluation of the incontinent women after a follow- up period of one year. This study is of special importance, since it is difficult to follow-up such patients in the long-term and it is important to verify whether the improvement achieved by the end of the treatment is maintained during the follow-up period. In this article, it was confirmed that the reduction in the index of urine loss was associated with a reduction in the risk of the need for surgery to correct stress urinary incontinence. However, these authors did not report the statistical results for the variables (electromyographic analysis of the PFM and urine loss index) analyzed immediately after intensive treatment.

At present, apart from the result for interventions being evaluated in an objective fashion, by looking at morbidity and mortality, subjective parameters are also used to determine what patients understand regarding quality of life and well-being. Urinary incontinence reduces the quality of life of patients because of their concern regarding urine loss in inappropriate settings, leading to psychological damage and restricted social relations.20-21 None of the studies analyzed used a validated quality of life questionnaire. However, the assessors questioned the incontinent women to determine the urine loss index, 17 the detrimental effects on social activity 17 and the patients' perceptions regarding UI. 16

Morkved et al. 17 used pressure biofeedback with the patients in the treatment group, while Berghmans et al. 16 and Aukee et al. 18 used electromyographic biofeedback. The two types of biofeedback have been shown to be effective in treatment of SUI. It can be seen, however, that, in recent studies of incontinent patients, electromyographic biofeedback is the first choice.22-23 Despite involving the use of cumbersome equipment, electromyographic biofeedback is more specific for muscle fibers, as it identifies electrical potential generated both in a state of rest (characterized by the base muscle tone) and during the phase of muscular contraction. It also allows the patient to monitor the contraction of the parasite muscles (such as the abdominal muscles) and the PFM, thereby allowing for the development of more selective and efficient activity of the perineal muscles. $24-25$

In two of the studies analyzed, ${ }^{17-18}$ the treatment was carried out by following up exercises carried out under guidance in the home of the patient. The patients periodically visited the physiotherapy where there was a training session. In only one study 16 was there outpatient treatment associated with the guided exercises in the patient's home. When the treatment carried out in the patient's home is supervised, it is possible to achieve greater adherence. Regular visits 
to the therapist provided greater motivation for the patient to continue to do the exercises and enabled the results to be monitored. ${ }^{26}$ However, it should be pointed out that there is some difficulty in controlling these patients, since, when the therapist does not directly monitor the session, it is difficult to be sure that the patient has done all the exercises for the length of time and the number times recommended. The fact that two studies included were not monitored directly by the therapist was a limitation of the articles covered by this systematic review.

The studies were not homogeneous so far as the treatment protocol and exercises used were concerned. The positioning of the patient for the perineal exercises and the length of treatment varied from study to study. The number of exercises carried out weekly and the frequency and duration of contractions of the PFM also varied. Two studies 16 17 described the PFM contraction protocol, covering both type I and type II muscle fibers. Only one study 18 did not describe the PFM contraction exercise protocol, although the authors point out that they used exercises for both slow and fast muscle fibers. In SUI, type II (rapid) fibers are the ones that are more damaged. The training of patients should give priority to this type of fiber, although patients should be encouraged to exercise the whole group of muscles, in order to help achieve conscious and effective contraction, as well as improving the contraction reflex. 27

Despite the differences found, all the articles analyzed reported similar results. The signs and symptoms of the women with SUI improved after treatment involving perineal exercises, both when these were in isolation and when they were combined with biofeedback. It should be noted, however, that no statistically significant differences were observed when comparing the two kinds of intervention immediately after the treatment period. ${ }^{16-18}$ Only one study 18 described that preservation of the integrity of PFM function during therapy is important for avoiding stress urinary incontinence corrective surgery, after a period of one year following intensive treatment. The percentage for cure and improvement of SUI was similar for all the treatment groups. ${ }^{16-18}$ There is, therefore, no

\section{References}

1. Abrams P, Cardoso L, Fall M, Griffiths D, Rosier P, Ulmsten U, Van Kerrebroeck P, Victor A, Wein A. The standardization of terminology of lower urinary tract function: report from the standardization sub-committee of the International Continence Society. Am J Obst Gynecol Int. 2002; 187: 116-26. scientific basis for the theory that the addition of biofeedback provides more effective treatment of SUI.

Berghmans et al. 16 report that therapy associated with biofeedback is important mainly in the first two weeks of treatment. Morkved et al. 17 claim that treatment with biofeedback provides greater motivation for the incontinent women to continue treatment and that it is thus a good option for clinical practice. Aukee et al. 18 report that biofeedback is beneficial in so far as it enables the therapist to check whether the patient has performed the exercises at home, while ensuring privacy and helping the patient to increase muscle activity.

The results found in this review are similar to those of Berghmans et al.28 who carried out a systematic review of studies published between 1980 and 1998. These authors used different criteria for the inclusion of articles from those used by the present systematic review and identified five randomized clinical trials that compared PFM exercises in isolation and in association with biofeedback. These authors found strong evidence that the addition of biofeedback does not increase the effectiveness of treatment for SUI patients.

\section{Conclusions}

The studies analyzed in this review suggest that biofeedback produces improvement of the symptoms in patients with SUI. However, when compared to PFM exercises in isolation, the addition of biofeedback does not appear to lead to any significant difference in the success of the treatment.

The scarcity of randomized clinical trials and the heterogeneity of the studies found were two of the limitations of this systematic review.

It is suggested that future studies be carried out in a controlled fashion, with adequate randomization and masking of the assessors. The samples should be homogenous and the evaluation methods and treatment used should be validated and standardized, thereby allowing for reliable comparison of the results.

2. Moreno AL. Fisioterapia em uroginecologia. 2 ed. São Paulo: Manole; 2009.

3. Minassian VA, Stewart WF, Wood GC. Urinary incontinence in women: variation in prevalence estimates and risk factors. Obst Gyneol. 2008; 111: 324-31. 
4. Peyrat L, Haillot O, Bruyere F, Boutin JM, Bertrand P, Lanson Y. Prevalence and risk factors of urinary incontinence in young and middle-aged women. BJU Int. 2002; 89: 61-6.

5. Danforth KM, Townsend MK, Lifford K, Curhan GC, Resnick NM, Grodstein F. Risk factors for urinary incontinence among middle-aged women. Am J Obst Gynecol. 2006; 194: 339-45.

6. Borello-France DF, Downey PA, Zyczynski HM, Rause CR. Continence and quality-of-life outcomes 6 months following an intensive pelvic-floor muscle exercise program for female stress urinary incontinence: a randomized trial comparing low- and high-frequency maintenance exercise. Phys Ther. 2008; 88: 1545-53

7. Castro RA, Arruda RM, Zanetti MRD, Santos PD, Sartori MGF, Girão MJBC. Single blind, randomized, controlled trial of pelvic floor muscle training, electrical stimulation, vaginal cones, and no active treatment in the management of stress urinary incontinence. Clinics. 2008; 64: 465-72.

8. Demirtürk F, Akbayrak T, Karakaya IC, Yüksel I, Kirdi N, Demirtürk F, Kaya S, Ergen A, Beksac S. Interferential current versus biofeedback results in urinary stress incontinence. Swiss Medical Wkly. 2008; 138: 317-21.

9. Neumann PB, Grimmer KA, Deenadayalan Y. Pelvic floor muscle training and adjunctive therapy for the treatment of stress urinary incontinence in women: a systematic review. BMC Women's Health. 2006; 6; 11: 1-28.

10. Kegel AH. Progressive resistance exercise in the functional restoration of the perineal muscle. Am J Obst Gynecol. 1948; 56: 238-49.

11. Dumoulin C, Hay-Smith J. Pelvic floor muscle training versus no treatment for urinary incontinence in women. Eur J Phys Rehabil Med. 2010; 1

12. Grosse D, Sengler J. Reeducação perineal: concepção, realização e transcrição em prática liberal e hospitalar. São Paulo: Manole; 2002.

13. Aukee P, Immonen P, Penttinen J, Laippala P, Airaksinen O Increase in pelvic floor muscle activity after 12 weeks' training: a randomized prospective pilot study. Urology. 2002; 60: 1020-4

14. Rett MT, Simoes JA, Herrmann V, Pinto CLB, Marques AA, Morais SS. Management of stress urinary incontinence with surface electromyography-assisted biofeedback in women of reproductive age. Phys Ther. 2007; 87: 136-42.

15. Maher CG, Sherrington C, Herbert RD, Moseley AM, Elkins M. Reliability of the Pedro Scale for rating quality of randomized controlled trials. Phys Ther. 2003; 83: 71321.

16. Berghmans LCM, Frederiks CMA, Frederiks RAB, Weil EHJ, Smeets LWH, van Waalwijk van Doorn ESC, Janknegt RA. Efficacy of biofeedback, when included with pelvic floor muscle exercise treatment, for genuine stress incontinence. Neurourol Urodyn. 1996; 15: 37-52.
17. Morkved S, Bo K, Fjortoft T. Effect of adding biofeedback to pelvic floor muscle training to treat urodynamic stress incontinence. Obstet Gynecol. 2002; 100: 730-9.

18. Aukee P, Immonen P, Laaksonen DE, Laippala P, Penttinen J, Airaksinen O. The effect of home biofeedback training on stress incontinence. Acta Obstet Gynecol Scan. 2004; 83: 973-7.

19. Haylen BT, Ridder D, Freeman RM, Swift SE, Berghmans B, Lee J, Monga A, Petri E, RizkDE, Sand PK, Schaer GN. An International Urogynecological Association (IUGA)/ International Continence Society (ICS) joint report on the terminology for female pelvic floor dysfunction. Neurourol Urodyn.2010; 29: 4-20.

20. Paschoal SMP. Qualidade de vida do idoso: elaboração de um instrumento que privilegia a sua opinião [dissertação]. São Paulo: Faculdade de Medicina da Universidade de São Paulo; 2000

21. Abreu, NS. Qualidade de vida na perspectiva de idosas submetidas à fisioterapia para incontinência urinária [dissertação]. Belo Horizonte: Escola de Educação Física da Universidade Federal de Minas Gerais; 2006.

22. Capelini MV, Riccetto CL, Dambros M, Tamanini JT, Herrmann V, Muller V. Pelvic floor exercises with biofeedback for stress urinary incontinence. International Brazilian Journal of Urology. 2006; 32: 462-9.

23. Gómez MFL, Abuín JMS, Criado FJG, Yagüez AG, Avisrror MU. Tratamiento de la incontinencia urinaria de esfuerzo con biofeedback perineal con electrodos de superfície. Actas Urol Esp. 2008; 32: 629-36.

24. Aksac B, Aki S, Karan A, Yalcin O, Isikoglu M, Eskiyurt N. Biofeedback and pelvic floor exercises for the rehabilitation of urinary stress incontinence. Gynecol Obst Invest. 2003; 56: 23-7.

25. Ribeiro RM, Rossi P, Pinotti JA. Uroginecologia e cirurgia vaginal. 1 ed. São Paulo: Roca; 2001.

26. Dedicação AC, Haddad M, Saldanha MES, Driusso P. Comparação da qualidade de vida nos diferentes tipos de incontinência urinária feminina. Rev Bras Fisioter. 2009; 13; $2: 116-22$.

27. Bernardes NO, Péres FR, Souza ELBL, Souza OL. Métodos de tratamento utilizados na stress urinary incontinence genuína: um estudo comparativo entre kinesiotherapy e eletroestimulação endovaginal. Rev Bras Ginecol Obst. 2000; 22: 49-54.

28. Berghmans LCM, Hendriks HJM, Bo K, Hay-Smithí EJ, Bies RA, Van Waalwijk Van Doorn ESC. Conservative treatment of stress urinary incontinence in women: a systematic review of randomized clinical trials. Br J Urol. 1998; 82: 181-91

Recebido em 3 de setembro de 2010

Versão final apresentada em 18 de maio de 2011

Aprovado em 20 de junho de 2011 